\title{
An assessment of systems and software engineering scholars and institutions (2002-2006)
}

\author{
W. Eric Wong ${ }^{1 *}$, T.H. Tse ${ }^{2}$, Robert L Glass ${ }^{3}$, Victor R. Basili ${ }^{4}$, T.Y. Chen ${ }^{5}$ \\ ${ }^{1}$ Department of Computer Science, The University of Texas at Dallas, \\ Richardson, TX 75083, USA \\ ${ }^{2}$ Department of Computer Science, The University of Hong Kong, \\ Pokfulam, Hong Kong \\ ${ }^{3}$ Computing Trends, 18 View Street, Paddington, QLD 4064, Australia \\ ${ }^{4}$ Department of Computer Science, University of Maryland, College Park, \\ MD 20742, USA \\ ${ }^{5}$ Faculty of Information and Communication Technologies, Swinburne \\ University of Technology, John Street, Melbourne 3122, Australia
}

\begin{abstract}
This paper summarizes a survey of publications in the field of systems and software engineering from 2002 to 2006. The survey is an ongoing, annual event that identifies the top 15 scholars and institutions over a five year period. The rankings are calculated based on the number of papers published in TSE, TOSEM, JSS, SPE, EMSE, IST, and Software. The top-ranked institution is Korea Advanced Institute of Science and Technology, Korea, and the top-ranked scholar is Magne Jørgensen of Simula Research Laboratory, Norway.
\end{abstract}

Keywords: Top scholars, top institutions, systems and software engineering, research publications

\section{Introduction}

Academic and industrial research institutions, along with their scholars, can be evaluated using many different criteria, based on either objective data or subjective surveys. Glass (1994) published the first report to answer the following two questions:

- Who are the most published scholars in the field of systems and software engineering?

- Which are the most published institutions?

A ranking system was devised based on the number of papers each institution and individual scholar, respectively, had published in the following six leading journals in the field of system and software engineering:

- Transactions on Software Engineering (TSE), IEEE

- Transactions on Software Engineering and Methodologies (TOSEM), ACM

- Journal of Systems and Software (JSS), Elsevier Science

- Software Practice and Experience (SPE), John Wiley \& Sons

- Software (SW), IEEE

- Information and Software Technology (IST), Elsevier Science

\footnotetext{
* Corresponding author. E-mail address: ewong@utdallas.edu.
} 
These journals were selected as the result of a survey of the editorial board of the Journal of Systems and Software conducted in 1991. This study has been repeated annually since then using the same set of journals and ranking formulae, with this being the thirteenth in the series. The objective is to answer the above questions and report the top scholars and institutions in systems and software engineering for 2002-2006.

A major difference between this year's report and the previous report for 2001-2005 (Wong et al., 2008) is the inclusion of the journal Empirical Software Engineering (EMSE), published by Springer. This change was made to emphasize the importance of applied software engineering research with a strong empirical component. Only the 2006 publications in EMSE are included, while those from 2003-2005 have not been considered. These earlier publications are omitted not because of resource or time constraints, but to ensure a smooth transition without disturbing the results of the previously published reports. Furthermore, conference proceedings are not included in the report as the result of an academic decision, not owing to limitations of the manual process as suggested by Ren and Taylor (2007).

Some critics argue that "quantity" should not be emphasized over "quality" or "value," but rather that the correctness, importance, novelty, and contribution of each paper should take precedence (Parnas, 2007). However, this style of assessment introduces subjective aspects such as the competence and biases of the reviewers (Meyer et al., 2009), and the significant time investment required to complete a thorough review of a paper substantially reduces the number of publications that can feasibly be surveyed. Counting citations is a proposed enhancement to the publication-counting method, although this also suffers from drawbacks. Parnas observes that a citation may imply critique rather than praise, or it may simply be a neutral inclusion by the author to prove familiarity with existing publications. Although the development of a more comprehensive and accurate assessment process for researchers and institutions is an important goal, the publication-based ranking method can still provide useful data (Geist et al., 1996).

In summary, we confine our study to the field of systems and software engineering, rather than attempting to address the entirety of computer science or information systems. Our publicationbased ranking is not implied to be the only meaningful evaluation mechanism, but it does provide

some quantitative guidance toward answering the two questions raised at the beginning of this section.

The rest of the paper is organized as follows: Section 2 reports our findings on the top scholars and Section 3 gives the top institutions. The correlation between top scholars and institutions is examined in Section 4.

\section{Top Scholars}

The top scholars in the field are shown in Table 1. The scores, based on their publication history in the seven journals we surveyed in 2002-2006, range from 10.50 to 4.00 . We have two ties in the rankings at the 5th and 15th places, respectively. This brings the total to 16 top scholars. Geographically, seven scholars are from the Asia-Pacific region, six are from Europe, and three are from the North America. Taiwan has the highest number of top scholars (three), followed by Norway, Sweden, Korea, and USA with two scholars each. China, United Kingdom, Canada, Greece, and Australia have one each.

Magne Jørgensen from Simula Research Laboratory, Norway, the top scholar from the 2001-2005 survey, once again is in first place with a score of 10.50. The runner-up is Hai Zhuge from the 
Chinese Academy of Sciences, China. The third place is Shih-Chien Chou from National Dong Hwa University, Taiwan.

Table 1. Top scholars in the field of systems and software engineering

\begin{tabular}{|c|c|c|c|c|c|c|c|c|c|c|}
\hline \multirow[t]{2}{*}{ Rank } & \multirow[t]{2}{*}{ Scholar } & \multicolumn{7}{|c|}{ Scores of each journal } & \multirow{2}{*}{$\begin{array}{l}\text { Total } \\
\text { score }\end{array}$} & \multirow{2}{*}{$\begin{array}{c}\text { Previous } \\
\text { rank }\end{array}$} \\
\hline & & TSE & TOSEM & $S P E$ & $J S S$ & $I S T$ & $S W$ & EMSE & & \\
\hline 1 & Magne Jørgensen, Simula Research Laboratory, Norway & 4.1 & 0 & 0 & 2 & 2.9 & 1.5 & 0 & 10.5 & 1 \\
\hline 2 & Hai Zhuge, Chinese Academy of Sciences, China & 0 & 0 & 0 & 7.1 & 1 & 0 & 0 & 8.1 & 2 \\
\hline 3 & Shih-Chien Chou, National Dong Hwa University, Taiwan & 0 & 0 & 0 & 5.4 & 2.5 & 0 & 0 & 7.9 & 4 \\
\hline 4 & Lionel Briand, ${ }^{\dagger}$ Simula Research Laboratory, Norway & 4.4 & 0 & 0.5 & 0.8 & 0.5 & 0 & 0 & 6.2 & 4 \\
\hline 5 & Barbara Kitchenham, Keele University, UK & 1.6 & 0 & 0 & 0.9 & 1.8 & 1.2 & 0 & 5.5 & 2 \\
\hline 5 & Per Runeson, Lund University, Sweden & 1.2 & 0 & 0 & 0.6 & 0.5 & 2.5 & 0.7 & 5.5 & - \\
\hline 7 & Chin-Wan Chung, Korean Adv. Inst. Sci. \& Tech., Korea & 0 & 0 & 0 & 3.4 & 2 & 0 & 0 & 5.4 & 8 \\
\hline 8 & Claes Wohlin, Blekinge Institute of Technology, Sweden & 1.2 & 0 & 0.7 & 1.1 & 0.7 & 0.8 & 0.7 & 5.2 & - \\
\hline 9 & James Miller, University of Alberta, Canada & 0.7 & 0 & 0 & 2.3 & 2 & 0 & 0 & 5.0 & 10 \\
\hline 10 & Richard Lai, La Trobe University, Australia & 1.4 & 0 & 0.7 & 1.3 & 1.5 & 0 & 0 & 4.9 & - \\
\hline 11 & Ioannis Stamelos, Aristotle University of Thessaloniki, Greec & 0.5 & 0 & 0 & 2.6 & 1.1 & 0 & 0.5 & 4.7 & 12 \\
\hline 12 & Jeff Tian, Southern Methodist Universirty, USA & 2.2 & 0 & 0 & 0.7 & 0 & 1.7 & 0 & 4.6 & 7 \\
\hline 13 & Myoung-Ho Kim, Korean Adv. Inst. Sci. \& Tech., Korea & 0 & 0 & 0 & 3 & 1.5 & 0 & 0 & 4.5 & 9 \\
\hline 14 & Chin-Yu Huang, National Tsing-Hua University, Taiwan & 0.5 & 0 & 0 & 3.7 & 0 & 0 & 0 & 4.2 & - \\
\hline 15 & Jan Bosch ${ }_{*}^{\ddagger}$ Intuit, USA & 0 & 0 & 1 & 2.5 & 0.5 & 0 & 0 & 4.0 & 13 \\
\hline 15 & Chin-Chen Chang, National Chung Cheng University, Taiwan & 0 & 0 & 0 & 4 & 0 & 0 & 0 & 4.0 & - \\
\hline
\end{tabular}

tionel Briand was previously with Carleton Utiversity, Cara ada

${ }^{\ddagger} \ddagger_{\text {Jan }}$ Bosch was previously with Uniwersity of Groningen, The Vetherlands

There are five "new" scholars that were not on the previous list: Per Runeson from Lund University, Sweden (tied for 5th place); Claes Wohlin from Blekinge Institute of Technology, Sweden (8th place); Richard Lai from La Trobe University, Australia (10th place); Chin-Yu Huang from National Tsing-Hua University, Taiwan (14th place); and Chin-Chen Chang from National Chung Cheng University, Taiwan (tied for 15th place).

Table 1 also shows the score with respect to each journal for each scholar. None of them had any publication in TOSEM from 2002 to 2006. The next most missed journals are SPE (12 out of 16) and SW (11 out of 16). Every scholar had at least one publication in JSS. The data on EMSE should not be misinterpreted because, as explained in Section 1, only the publications in 2006 of that journal are included.

Table 2. Research focus of top scholars

\begin{tabular}{|c|c|c|}
\hline Rank & Scholar & Research focus \\
\hline 1 & Magne Jørgensen & Judgmental processes in software cost estimation \\
\hline 2 & Hai Zhuge & Internet-based systems \\
\hline 3 & Shih-Chien Chou & $\begin{array}{l}\text { Software development process, software reuse, information flow control, and agent-based software } \\
\text { development }\end{array}$ \\
\hline 4 & Lionel Briand & Software testing and model-driven development \\
\hline 5 & Barbara Kitchenham & Cost estimation, metrics, and evidence-based software engineering \\
\hline 5 & Per Runeson & Empirical software engineering, testing, inspections, and software quality management \\
\hline 7 & Chin-Wan Chung & Database, web, and multimedia \\
\hline 8 & Claes Wohlin & $\begin{array}{l}\text { Empirical software engineering, software management, software process, and requirements } \\
\text { engineering }\end{array}$ \\
\hline 9 & James Miller & Web engineering, security and privacy, and software testing \\
\hline 10 & Richard Lai & $\begin{array}{l}\text { Software process improvement, software measurement and testing, requirements engineering, } \\
\text { component-based software engineering, and human centered computing }\end{array}$ \\
\hline 11 & Ioannis Stamelos & Open source software and empirical software engineering \\
\hline 12 & Jeff Tian & Testing and quality improvement, measurement and risk management, and web quality engineering \\
\hline 13 & Myoung-Ho Kim & Database and distributed systems \\
\hline 14 & Chin-Yu Huang & Software reliability, software testing, and software metrics \\
\hline 15 & Jan Bosch & $\begin{array}{l}\text { Software architecture design and assessment, software product families, software variability } \\
\text { management, and strategic software reuse }\end{array}$ \\
\hline 15 & Chin-Chen Chang & Data engineering, Database systems, Computer cryptography and Information security \\
\hline
\end{tabular}


Table 2 lists the key words that each top scholar feels best describe their research focus.

\section{Top Institutions}

The top 15 institutions in the field are shown in Table 3. The scores, based on their publication history in the seven journals we surveyed from 2002-2006, range from 33.38 to 11.73. All the top institutions except for Simula Research Laboratory are from academia. Geographically, eight of the institutions are from Asia (two from Korea, two from Taiwan, two from Hong Kong, one from Singapore and one from China), four from USA, and three are from Europe (with one each from Greece, Sweden and Norway, respectively). Korea Advanced Institute of Science and Technology tops the list with a score of 33.38. It was also in first place in the last survey (20012005). The runner-up is Simula Research Laboratory in Norway with a score of 22.35 which was listed at the third place in the 2001-2005 survey. The National Chiao Tung University in Taiwan with a score of 20.75 was the runner-up last time but slipped to third place this year.

Blekinge Institute of Technology, Sweden and Chinese Academy of Sciences, China are at the 11th and 13th places for this survey but were not on the previous list. Other notable advancements are made by the University of Maryland from 11th to 4th, Hong Kong Polytechnic University from 10th to 6th, Aristotle University of Thessaloniki from 13th to 7th, and National Cheng Kung University from 15th to 8th. Giving the most ground are the Georgia Institute of Technology from 6th to 15th, and City University of Hong Kong from 8th to 12th.

With respect to each journal, 12 of the 15 top institutions do not have any publications in TOSEM from 2002 to 2006, while only two (Seoul National University, Korea and Chinese Academy of Sciences, China) do not have any publications in TSE. The next most missed journal is $S W$ (8 out of 15) followed by SPE (4 out of 15). All 15 top institutions have publications in JSS and IST. As explained in Section 1, the data on EMSE should not be misinterpreted.

Table 3. Top institutions in the field of systems and software engineering

\begin{tabular}{|c|l|l|c|c|}
\hline Rank & Institution & ournals in which published & Score & Prev. rank \\
\hline 1 & Korea Advanced Institute of Science and Technology, Korea & All but TOSEM, SW, and EMSE & 33.38 & 1 \\
\hline 2 & Simula Research Laboratory, Norway & All but TOSEM and SPE & 22.35 & 3 \\
\hline 3 & National Chiao Tung University, Taiwan & All but TOSEM, SW, and EMSE & 20.75 & 2 \\
\hline 4 & University of Maryland, USA & All & 18.50 & 11 \\
\hline 5 & Seoul National University, Korea & All but TOSEM, TSE, SW, and EMSE & 14.79 & 4 \\
\hline 6 & Hong Kong Polytechnic University, Hong Kong & All but TOSEM, SW, and EMSE & 14.61 & 10 \\
\hline 7 & Aristotle University of Thessaloniki, Greece & All but TOSEM, SPE, and $S W$ & 13.87 & 13 \\
\hline 8 & National Cheng Kung University, Taiwan & All but TOSEM, SPE, SW, and EMSE & 13.54 & 15 \\
\hline 9 & Iowa State University, USA & All but TOSEM and $E M S E$ & 13.46 & 7 \\
\hline 10 & University of Texas at Dallas, USA & All but TOSEM and $E M S E$ & 12.94 & 9 \\
\hline 11 & Blekinge Institute of Technology, Sweden & All but TOSEM & 12.59 & - \\
\hline 11 & City University of Hong Kong, Hong Kong & All but SW and EMSE & 12.16 & 8 \\
\hline 13 & Chinese Academy of Sciences, China & All but TOSEM, TSE, SW, and EMSE & 12.16 & - \\
\hline 14 & National University of Singapore, Singapore & All but TOSEM, SPE, and $E M S E$ & 11.78 & 14 \\
\hline 15 & Georgia Institute of Technology, USA & All but $E M S E$ & 11.73 & 6 \\
\hline
\end{tabular}




\section{Correlation between Top Institutions and Top Scholars}

We have also analyzed the relationship between the ranking of an institution and the number of top scholars housed there, the results of which are shown in Table 4. Five ${ }^{1}$ of the 15 institutions in 2002-2006 had at least one top scholar, with the 1st place Korea Advanced Institute of Science and Technology having two: Chin-Wan Chung (7th place) and Myoung-Ho Kim (13th place). Although an institution's score can be improved by the presence of top scholars, this is not the only important factor in achieving a high ranking.

Table 4. Top institutions and top scholars

\begin{tabular}{|c|l|l|}
\hline Rank & Institution & Top scholar \\
\hline 1 & Korea Advanced Institute of Science and Technology, Korea & Chin-Wan Chung and Myoung-Ho Kim \\
\hline 2 & Simula Research Laboratory, Norway & Magne Jørgensen and Lionel Briand \\
\hline 3 & National Chiao Tung University, Taiwan & \\
\hline 4 & University of Maryland, USA & \\
\hline 5 & Seoul National University, Korea & \\
\hline 6 & Hong Kong Polytechnic University, Hong Kong & \\
\hline 7 & Aristotle University of Thessaloniki, Greece & Ioannis Stamelos \\
\hline 8 & National Cheng Kung University, Taiwan & \\
\hline 9 & Iowa State University, USA & \\
\hline 10 & University of Texas at Dallas, USA & \\
\hline 12 & Blekinge Institute of Technology, Sweden & Claes Wohlin \\
\hline 12 & City University of Hong Kong, Hong Kong & \\
\hline 13 & Chinese Academy of Sciences, China & Hai Zhuge \\
\hline 14 & National University of Singapore, Singapore & \\
\hline 15 & Georgia Institute of Technology, USA & \\
\hline
\end{tabular}

\section{Acknowledgment}

We extend our thanks to Yan Shi of the University of Texas at Dallas for her help in collecting and validating the data. Miss Shi also provided the assistance for the last survey for 2001-2005.

\section{References}

Geist, R. M., Chetuparambil, M., Hedetniemi, S., and Turner, A. J., 1996. Computing research programs in the US. Communications of the ACM 39 (12), 96-99.

Glass, R. L., 1994. An assessment of systems and software engineering scholars and institutions. Journal of Systems and Software 1, 63-67.

Meyer, B., Choppy, C., Staunstrup, J., and van Leeuwen, J., 2009. Viewpoint: research evaluation for computer science. Communications of the ACM 52 (4), 31-34.

Parnas, D. L., 2007. Stop the numbers game. Communications of the ACM 50 (11), 19-21.

Ren, J. and Taylor, R. N., 2007. Automatic and versatile publications ranking for research institutions and scholars. Communications of the ACM 50 (6), 81-85.

Wong, W. E., Tse, T. H., Glass, R. L., Basili, V. R., and Chen, T. Y., 2008. An assessment of systems and software engineering scholars and institutions (2001-2005). Journal of Systems and Software 81 (6), 1059-1062.

1Simula Research Laboratory (2nd place) currently houses two top scholars: Magne Jørgensen (1st place) and Lionel Brand (4th place), but only Dr. Jørgensen was employed there during the 2002-2006 period under consideration. 
W. Eric Wong received his Ph.D. in Computer Science from Purdue University. He is currently an Associate Professor in the Department of Computer Science at the University of Texas at Dallas. Dr. Wong is a recipient of the Quality Assurance Special Achievement Award from Johnson Space Center, NASA (1997). Prior to joining UTD, he was with Telcordia Technologies (formerly Bellcore) as a Senior Research Scientist and as the project manager in charge of the initiative for Dependable Telecom Software Development. Dr. Wong's research focus is on the development of technology to help practitioners produce high quality software at low cost. In particular, he is doing research in the areas of software testing, maintenance, safety, and metrics. He is on the editorial board of Journal of Systems and Software. He has been also a standing committee member of COMPSAC since 2007, an member of the Administrative Committee of the IEEE Reliability Society since 2008, and has served or is serving as Program and General Chair of many conferences such as COMPSAC 2010 and 2004, SSIRI 2009, QSIC 2007, ACM SAC SE Track 2007-2010, ISSRE 2005, SEKE 2005, etc.

T. H. Tse is a Professor in Computer Science at The University of Hong Kong. He received his Ph.D. in Information Systems from the London School of Economics and was a Visiting Fellow at University of Oxford. He is a member of the editorial board of Journal of Systems and Software, Software Testing, Verification and Reliability, and Journal of Universal Computer Science. He has been the steering committee chair of QSIC since 2003, a steering committee member of COMPSAC since 2002, the general chair of SOSE 2007, the program chair of COMPSAC 2001, and a program co-chair of APAQS 2000. He is a fellow of the British Computer Society, a fellow of the Institute for the Management of Information Systems, a fellow of the Institute of Mathematics and its Applications, and a fellow of the Hong Kong Institution of Engineers. He was selected for a "Ministry of Education Nominated State Science and Technology Award”' in China. He was decorated with an MBE by The Queen.

Robert L. Glass is president of Computing Trends, publishers of The Software Practitioner newsletter, and an Honorary Professor of Software Engineering at Griffith University, Brisbane, Australia. He has been active in the field of computing and software for over 50 years, largely in industry (1954-1982 and 1988-2005), but also as an academic (1982-1988 and 2005-present). He is the author of over 25 books and 90 papers on computing subjects, Editor of The Software Practitioner, Editor Emeritus of Elsevier's Journal of Systems and Software, and a columnist for several periodicals including the two leading journals in his field, Communications of the ACM (the "Practical Programmer” column) and IEEE Software (“The Loyal Opposition"). He was for 15 years a Lecturer for the ACM (the leading computing professional society), and was named a Fellow of the ACM in 1998. He received an honorary Ph.D. from Linkoping University in Sweden in 1995. He describes himself by saying "my head is in the academic area of computing, but my heart is in its practice.”

Victor R. Basili is a Professor of Computer Science at the University of Maryland, College Park. He holds a Ph.D. in Computer Science from the University of Texas, Austin and is a recipient of two honorary degrees from the University of Sannio, Italy (2004) and the University of Kaiserslautern, Germany (2005). He was Director of the Fraunhofer Center for Experimental Software Engineering - Maryland and a director of the Software Engineering Laboratory (SEL) at NASA/GSFC. He works on measuring, evaluating, and improving the software development process and product. Dr. Basili is a recipient of several awards including a 1989 NASA Group Achievement Awards, the 2000 Outstanding Research Award from ACM SIGSOFT, and the 2003 Harlan Mills Award for the IEEE Computer Society, and the Fraunhofer Medal. He has authored over 250 journal and refereed conference papers, has served as Editor-in-Chief of IEEE TSE and the Springer Journal of Empirical Software Engineering. He is an IEEE and ACM Fellow. 
T. Y. Chen received his B.Sc. and M.Phil. degrees from the University of Hong Kong, M.Sc. degree and DIC from Imperial College of Science and Technology, and Ph.D. degree from the University of Melbourne. He is a Professor of Software Engineering in the Faculty of Information and Communication Technologies, Swinburne University of Technology, Australia. He is a member of the editorial board of Journal of systems and Software and Software Testing, Verification and Reliability. He served as a member of the College of Experts for the Australian Research Council for the years 2005 and 2006. His research interests include software testing, debugging, software maintenance, and software design. 